\title{
CUITURA. SOCIEDADE CONTEmPORÂnEA E
}

PERSPECTIVAS DO CORPO DIGITAL nO CIBERESPACO:

SIGNIFICAÇÕES INTERDISCIPUIARRES

\author{
Eduardo Fofonca ${ }^{17}$
}

\section{RESUMO}

$\mathrm{O}$ artigo objetiva discutir as perspectivas do corpo e suas inter-relações no ciberespaço - em conexões e significações atualizadas na cultura e sociedade contemporânea, caracterizando uma análise da onipresença do corpo nas representações, interações e pluralidades das relações que são estabelecidas, sobretudo, no meio digital. Diante disso, busca-se por meio de um referencial teórico interdisciplinar, considerar mecanismos que apontam o corpo como produtor de sentidos, demonstrando um contraponto às novas tecnologias digitais para se pensar o corpo digital na cultura contemporânea em múltiplas interfaces: na expressão dos sentimentos de amor e das relações de cibersexualidade através das interações homem/máquina, nas caracterizações e nas representações da pós-modernidade.

Palavras-chave: Cultura. Sociedade Contemporânea. Corpo Digital. Tecnologias. Interdisciplinaridade.

\section{INTRODUÇÃO}

A manifestação do corpo na contemporaneidade tem despertado muito interesse de pesquisadores em diversas áreas do conhecimento e possibilita ampliações de diferentes significados que incluem o contexto da cultura de um modo geral. Segundo Garcia (2005), a ideia de cultura, atualmente estratifica uma série de questões paulatinas no desdobramento conceitual sobre o corpo. Para o autor, a recorrência desse tema implica o processo de criação comunicativa e artística contemporânea em uma rede de enunciações ambígua, sincrética e

17 Doutorando em Educação, Arte e História da Cultura pela Universidade Presbiteriana Mackenzie, São Paulo e mestre em Comunicação e Linguagens pela Universidade Tuiuti do Paraná. Bolsista do Instituto Presbiteriano Mackenzie. Coordenador Pedagógico Regional da Editora Positivo, Paraná, Brasil. E-mail: eduffk@bol.com.br 
performática. Assim, esta dinâmica do corpo emerge na interação/mediação do estado híbrido entre arte, comunicação, ciência e tecnologia.

As diversas noções de corpo que podem ser observados em estudos contemporâneos evidenciam a responsabilidade de permear diferentes pontos de vista, sobretudo sob a ótica interdisciplinar. No seu amplo e complexo panorama de contextualizações, o corpo na cultura contemporânea, torna-se um dispositivo de múltiplos olhares para a compreensão das relações, que por meio dele, são estabelecidas na atual sociedade.

É a partir destes efeitos que possuem o corpo como pano de fundo das discussões sobre a cultura contemporânea que, a análise em questão, através de um referencial teórico interdisciplinar, considera mecanismos que apontam o corpo como produtor de sentidos. No entanto, o que interessa para a esta discussão é a tentativa de demonstrar um contraponto às novas tecnologias digitais, interligando o corpo aos mecanismos do digital das novas tecnologias e as possíveis formas e relações que por meio das interações homem/máquina (re) criam novas formas de relacionamentos.

Desta forma, chama-se a atenção que esta análise, além de uma busca teórica por pesquisadores que desvendam significações sobre o corpo e suas inter-relações com o digital, pretende-se utilizar como artefato de análise, de forma mais representativa a mídia impressa da "Revista Época" ${ }^{18}$ da Editora Globo, de 2009, na qual traz uma reportagem sobre as relações do corpo digital, ampliando as discussões sobre as fragilidades dos laços humanos construídas numa plataforma digital de relacionamentos. A reportagem analisou por meio da experiência de um jornalista brasileiro que vivenciou as inúmeras formas de relações (afetividade, amor, sexo, namoro) heterossexuais no ciberespaço. Este recorte da experiência do jornalista ao vivenciar inúmeras formas de relacionamentos na plataforma digital de relacionamentos nos possibilitará, ao

18 Para saber mais sobre a reportagem, acessada em 10 de maio de 2012: http://revistaepoca.globo.com/Revista/Epoca/0,EMI93880-15228,00MINHA+VIDA+AMOROSA+NA+INTERNET.html. 
tecer desta abordagem, uma reflexão no campo prático acerca das relações que são estabelecidas na interação homem/máquina, junto ao ciberespaço.

Eminentemente, o foco desta proposição de estudo direciona-se às perspectivas do corpo digital e sua inter-relações afetivas eróticas, sexuais, culturais e sociais, com expressões de negociações de distintas abordagens conceituais (BAUMAN, 1998, 2004; GARCIA, 2005; GIDDENS, 1992; PERNIOLA, 1998) na produção de sentidos na cultura e na arte, em especial nas suas conjunturas ampliadas pelas tecnologias digitais.

\section{O CORPO E O CORPO DIGITAL NA CULTURA CONTEMPORÂNEA: UM OLHAR INTERDISCIPLINAR ${ }^{19}$}

As marcas da cultura contemporânea potencializam o olhar interdisciplinar sobre o corpo. Como exercício interdisciplinar de adentrar de modo crítico, em toda a complexidade e conexão dos estudos contemporâneos, "arrisca-se afirmar que o corpo parece ser o foco determinante para instaurar a identidade cultural pós-moderna, seja a partir das ultrapassadas classificações de gênero, classe social ou faixa etária ou, até mesmo, a partir das "novas/outras" condições adaptativas intermediadas pela mídia" (GARCIA, 2005, p.24).

A sociedade contemporânea, cada vez mais, interessa-se pela várias mediações que contemplam consumo exacerbado, retardamento do envelhecimento corporal, saúde e estética corporal, produção de sentidos, expressão de materialidade. Na história da ciência e do próprio homem, nunca se pensou tanto na manifestação do corpo, principalmente por sofrer influências na materialidade, da técnica e da tecnologia e, sobretudo, das novas mídias digitais.

O campo das Ciências Sociais permeiam estudos sobre e corpo e sua representação sociocultural. Para o campo da comunicação, as contribuições

19 De acordo com Leis (2005), a prática da interdisciplinaridade não supõe uma negação das bases epistemológicas das disciplinas, como no caso da transdisciplinaridade, mas também não pretende deixar intacto o monopólio epistemológico das disciplinas, como no caso da multidisciplinaridade. [...] A prática da interdisciplinaridade supõe o equilíbrio de dois aspectos, por um lado, uma visão integradora de diversas disciplinas e, por outro, um salto cognitivo que não esteja pressuposto em qualquer somatória de abordagens disciplinares (p.110). 
sobre o corpo são baseadas nos estudos da mensagem tangencial que ele transmite, principalmente pela evocação da imagem da corporalidade como mensagem, procedente do inteligível.

De acordo com Garcia (2005), a materialidade do corpo é a materialidade informacional da cultura e do sujeito, contribuindo ainda na expressão visual, com o desenvolvimento da reflexão crítica, cuja constante exterioridade, mediação e corporalidade equacionam a noção de transcorporalidades ${ }^{20}$.

Segundo Camargo e Hoff (2002), o corpo pode ser considerado uma caixa complexa de informações, que contém diferentes saberes a respeito do homem e do mundo. Assim, a noção de transcorporalidade, dito por Garcia (2005), poderá contribuir para a compreensão desta caixa complexa de informações. O corpo, para Garcia, torna-se um microcosmo a ser desvelado também na instância que pode ser contextualizado no seu contraponto dialético - o macrocosmo e, portanto, busca o seu desconhecido.

Nesta esfera subjetiva de produção de sentidos sobre o corpo e a cultura contemporânea, organiza-se um diálogo entre a arte, a comunicação e suas conexões com as negociações que realocam o corpo como um dispositivo. Este entrelaçamento entre corpo e cultura contemporânea, parafraseando Garcia (2005), além de uma expressão dos processos interdisciplinares, contribui para o entendimento do objeto corpóreo como órgão aglutinador e mediador de informações, produzindo a (re) significação de dados na ordem da expressão comunicacional da experiência humana.

No campo da arte contemporânea, os parâmetros são contundentes e bem mais abertos. Observamos grande número de artistas interessados em registrar o corpo como tema de suas experimentações e incursões conceituais tanto em fotografias, filmes, esculturas e pinturas quanto em instalações e performances. A radicalidade dos artistas que tentam estender ao máximo a potencialidade física e representacional do corpo como as cirurgias estéticas performáticas da francesa Orlan e os

20 Categoria crítica capaz de agregar diferentes possibilidades para pensarmos as manifestações do corpo contemporâneo. Seja na publicidade, na mídia, na arte ou no cotidiano, essas transcorporalidades surgem como estados de performance, em que o corpo ressalta suas nuanças poéticas, estéticas, plásticas, que evidenciam a discursividade visual estratégica (GARCIA, 2005, p.13). 
adventos de próteses tecnológicas de Sterlac, a fotografia paródica e deslocada de Cindy Sherman ou ainda o (re)modelamento de Matthew Barny, os cadáveres do anatomista Gunter Von Hagens e o corpo digitalizado do projeto Voxel Man (Santoro, 2004). Há uma efervescente combinatória de procedimento poéticos (no fazer-saber) dos artistas contemporâneos que visam ultrapassar o público com inquietações que transpõem em novidades de uma arte mais carnal e tecnológica (GARCIA, 2005, p.35).

Na medida em que estas alternâncias interdisciplinares são criadas, várias análises para revisão de diferentes graus de possibilidades corpóreas ampliam a esfera explícita deste objeto. Nesta ampliação, as reiterações de novos paradigmas, ambientados pela cultura contemporânea de inclusão digital fazem o corpo como uma representação complexa de sistema que deflagram a diversidade substancial de corpo na atualidade, surgindo novas experiências de troca, manifestações e interfaces (homem/máquina), que o corpo expressa diante da cultura contemporânea (digital e tecnológica).

Entre os universos da arte, da ciência e da comunicação, somos instigados a compreender que os procedimentos de mediação do corpo remetem a configuração de uma identidade contemporânea, na qual pode se dar partir de uma concepção entre o real e o virtual e ainda nas relações identitárias do ciborgue.

Pode-se desmistificar, neste âmbito de discussão, que o entrecruzamento entre os campos de conhecimento que conciliam a dimensão tecnológica, trazendo como conseqüências um corpo hipermediático, no qual altera relações e identidades. As relações que são estabelecidas, neste contexto, vão do humano ao não-humano, ou ainda, ao pós humano ${ }^{21}$. Pensa-se, contudo, que as proposições deste conceito de pós-humano podem fomentar um estado de hibridismo que se contextualiza pela condição de adaptação do corpo ao corpo digital. Assim, contesta-se que a troca postulada pelas intervenções no campo

21 Em 1952, Van Vogt sugeriu o termo pós-humano, para designar uma outra raça criada pelo ser humano em seu conto Slan. Bruce Sterling empregou a expressão em Schizmatrix (1985), relançando-a em novo contexto de desenvolvimento tecnológico. Em bases ensaísticas, o sentido que o termo passou a ter em seguida parece, porém, ter sido explorado pela primeira vez por James Bernal, em 1929 (The World, the Flesh and the Devil: An Enquiry into the Future of theThree Enemies of the Rational Soul). 
tecnológico redimensiona o corpo para o espaço de virtualização, isto é, por meios das relações que são estabelecidas também no ciberespaço.

\section{ALGUNS EXPERIMENTOS VIRTUAIS}

Com o desenvolvimento das tecnologias da informação e da comunicação, no qual a Internet pode ser considerada a espinha dorsal, a comunicação mediada pelo computador ( $\mathrm{CMC}$ ) insere os sujeitos contemporâneos no campo das interações humanas, com novos limites, objetivos e possibilidades. A sociabilidade proporcionada pela rede das redes pode ser originalmente observada pelo que Simmel (1983) chama de noção de sociabilidade. Esta investigação é amplamente utilizada por pesquisadores de mídia, principalmente, quando se refere aos objetos de pesquisa oriundos dos âmbitos tecnológicos de comunicação e de informação.

Nesse sentido, torna-se importante considerar que a atual sociedade convive, a todo o momento, com a mídia digital. Na sociedade contemporânea, as tecnologias digitais têm como principal referência, a virtualidade. Na perspectiva de Pierre Lévy (1995), surgiram, então, como a infra-estrutura do ciberespaço um novo espaço de comunicação, de sociabilidade, de organização e de transição, mas também novo mercado da informação e do conhecimento.

Com este efeito, observa-se que o mundo está se estruturando em novas relações, que no ciberespaço, foi batizada por alguns pensadores (LÉVY, 1995; LEMOS, 2002) como cibercultura ${ }^{22}$. De acordo com Lévy (1995), a cibercultura é o conjunto de técnicas (materiais e intelectuais), de práticas, de atitudes, de modos de pensamento e de valores que se desenvolvem juntamente com o ciberespaço.

Os estudos inerentes à cibercultura decorrem da reflexão inicial de que elas se constituem num processo contínuo, isto é, estão em construção. E nesse

22 Para Kerckhove (2009), à medida que penetrarmos nas realidades virtuais da tela com capacetes de realidade virtual, "datagloves" e "datasuits", estamos entrando numa terceira era midiática: a cibercultura. A cibercultura é o produto da multiplicação da massa pela velocidade, com as tecnologias do vídeo intensificadas pelas tecnologias informáticas (2009, p.143). 
contexto, discutem-se algumas questões de relevância, no que diz respeito às novas formas de comunicação e suas interfaces. Lemos (2002) considera que a disseminação da internet, a partir da década de 1990, possibilitou o início de mais um processo ainda em curso, a modificação das relações de tempo e espaço.

A tecnologia digital pode ser um mecanismo de aproximação das pessoas, com novos sentidos nas relações humanas, extraindo a interação integral ou parcialmente do face a face e incluindo novas sensibilidades nas interações homem/máquina. Nesse âmbito comunicacional e tecnológico, surgem o amor virtual, a cibersexualidade e ainda inúmeras outras possíveis formas de relacionamento no ciberespaço. Isto mostra como as tecnologias da informação e da comunicação afetam as experiências humanas de diversos modos nos atuais tempos e espaços.

Nessa perspectiva, para organizar um pouco essa compreensão, propõemse refletir sobre como os espaços abstratos da Internet podem afetar a experiência amorosa, independente do meio (site, chat, email, redes sociais, plataformas de relacionamento amoroso ou de sexo casual, etc) por meio dos quais os diversos sujeitos atuem. Neste contexto, seria importante pensar em algumas concepções sociológicas (Giddens, 1992; Bauman 1998, 2004) que refletem acerca da pósmodernidade e suas influências não somente como momento histórico, mas estilo de vida das pessoas nesta sociedade líquido-moderna.

De acordo com Giddens (1992), as conseqüências da modernidade "partem da compreensão da natureza da própria modernidade, para concluir que o que chamamos 'pós-moderno' é identificado como um período em que 'as consequências da modernidade' estão se tornando mais radicalizadas e universalizadas do que antes" (GIDDENS; 1992 p. 13). A perspectiva de Bauman (2005), o sentido da pós-modernidade é explicado pela metáfora da "liquidez", explicando o sentido desta modernidade imediata, leve e fluída, permeada pelas profundas mudanças em todos os aspectos da vida humana. A crise das ideologias fortes, "pesadas", "sólidas", típicas da modernidade produziu, do ponto 
de vista cultural, um clima fluido, líquido, leve, caracterizado pela precariedade, incerteza, rapidez de movimento.

\begin{abstract}
Os líquidos, diferentemente dos sólidos, não mantêm sua forma com facilidade [...] Enquanto os sólidos têm dimensões especiais claras, mas neutralizam o impacto e, portanto, diminuem a significação do tempo (resistem efetivamente a seu fluxo ou tornam irrelevante), os fluidos não se atêm muito a qualquer forma e estão constantemente prontos (e propensos) a mudá-la (BAUMAN, 2004a, p.8).
\end{abstract}

$\mathrm{Na}$ análise de Bauman (2004), duas características fazem da modernidade líquida algo de novo e diferente, comparado ao modelo cultural anterior. A primeira é o desmoronamento da antiga ilusão moderna, ou seja:

Da crença de que há um fim do caminho em que andamos, um télos alcançável da mudança histórica, um Estado de perfeição a ser atingido amanhã, no próximo ano ou no próximo milênio, algum tipo de sociedade boa da ordem perfeita em que tudo é colocado no lugar certo [...] do completo domínio sobre o futuro (BAUMAN, 2004, p.37).

Talvez seja este o sentido mais profundo, do ponto de vista filosófico, da metáfora da liquidez, que Bauman (2004) analisa em várias circunstâncias. A sociedade líquida não desceu do céu, não se produziu do nada, improvisadamente, mas foi o fruto maduro do desmoronamento da modernidade, ou seja, do processo do derretimento dos sólidos formados e elaborados na modernidade.

Além disso, de acordo com as correntes da pós-modernidade, as relações pessoais, reais ou virtuais, as pessoas podem estar interessadas questão do tempo ou da duração. Ou seja, em duas formas diferentes de relação, de um lado as relações consideradas curtas, com consequências de se esgotar num curto lapso de tempo, como por exemplo, um encontro real de uma noite; quase no mesmo sentido, as relações efêmeras e instáveis, ou por outro lado então, as relações estáveis, como a utilização da Internet na busca de um futuro parceiro, com fins de namoro ou casamento.

Neste lugar de sociabilidade existe um recanto de conversação, onde se pode comunicar, em tempo real, unicamente através da escrita, e que permite a 
cada apresentação, a representação da sua identidade o mais próximo ou mais distante possível da realidade dos usuários.

Para a ilustração destas formas de relacionamento no ciberespaço será utilizado a plataforma intitulada PP (Par Perfeito.), que é administrada pelo grupo francês Meetic, no Brasil. Segundo dados da Revista Época de setembro de 2009, da editora Globo, o Brasil foi o país em que o grupo Meetic mais cresceu no mundo no primeiro semestre de 2009. O namoro na internet e as relações humano-tecnológicas se tornaram fenômenos de massa no mundo todo.

Nos fragmentos abaixo observam-se uma pouco da experiência vivida pelo jornalista, citado na introdução desta proposição de estudo, que ganhou destaque nas páginas da revista de circulação nacional com o título "Minha vida amorosa na internet":

Há muita mentira e fingimento na internet. Mas $\mathrm{S}$. era mesmo um mulherão. Vestia-se com elegância simples. Calça jeans, blusa branca tomara que caia e tênis branco All Star sem meia. Brilho nos lábios, maquiagem leve, olhos negros.

- E aí, ficou decepcionado? Sou muito diferente do que imaginava?, perguntou.

- Imagine! Você é muito mais interessante ao vivo que no site. Maravilhosa!, respondi.

Conversamos muito, nos despedimos com um beijo no rosto. Na mesma semana, jantamos num restaurante japonês na Vila Olímpia, Zona Sul de São Paulo, ao som de jazz e à luz de velas. Ali foi o primeiro beijo. Depois, saímos mais uma ou duas vezes... e começamos a namorar. O sexo não era uma obsessão para nós. Aconteceu de forma natural, na hora certa.

Minha relação com $S$. foi a melhor experiência que vivi nos 15 meses que passei no PP, apelido afetuoso do Par Perfeito, o maior site de relacionamentos amorosos do Brasil. Eu tinha preconceito contra 0 namoro virtual. Achava que só "encalhados" entravam nisso. Mas resolvi arriscar. Não me cadastrei no PP para escrever esta reportagem. Entrei lá pelo mesmo motivo que todo mundo entra: para ver o que acontecia. Separado, sem filhos, mais de 40 anos e com uma situação financeira relativamente estável, não tinha muito a perder. No mínimo, me divertiria. De repente, poderia conhecer uma mulher interessante.

Desde maio do ano passado, quando me cadastrei, mais de 7 mil mulheres acessaram meu perfil. Devo ter visto fotos de mais de 15 mil mulheres. Acessei 3 mil perfis. Recebi e-mails de 1.200. Só tive contato com as que eu mesmo busquei. Mandei mensagens para 500. Recebi respostas de 85. Conheci 18 pessoalmente. Namorei - e transei com seis. 
Todas as mulheres citadas nesta reportagem estão protegidas pelo anonimato. Eu também - ainda mantenho meu perfil no PP, mas o retratado nesta reportagem é apenas ilustrativo.

Além de $\mathrm{S}$., com quem tive um envolvimento mais sério, namorei uma decoradora de interiores, duas executivas e duas professoras de colégios tradicionais de São Paulo, ambas formadas em pedagogia. Não me envolvi profundamente com nenhuma. Mas vivi pequenos romances com todas. Com duas dessas cinco, fui para a cama mais de uma vez. Foi bom para mim - e espero que para elas também. Depois, por razões que só o coração pode explicar, as relações perdiam o encanto, e acabava me afastando.

As outras 12 mulheres do PP que conheci pessoalmente, mas não namorei, eram quase todas interessantes, atraentes e divertidas. Só que a relação não decolou. Entre elas havia executivas, uma advogada, uma produtora cultural de uma tradicional família paulista e duas jornalistas uma delas trabalha numa grande rede de TV do país e a outra é assessora de imprensa de uma multinacional. Vi também no site várias pessoas que já conhecia. Encontrei uma ex-vizinha dos tempos de adolescência, outra jornalista conhecida e duas funcionárias da Editora Globo, que publica ÉPOCA. Quando encontrava ou era procurado por alguém que conhecia, eu fazia o possível para evitar o contato. Ao contrário do que imaginava, vi que havia mulheres de todos os tipos no site. Bonitas, inteligentes e com ótimo nível cultural, que pareciam se encaixar em meu mundo com perfeição. Logo me dei conta de como a internet é uma boa alternativa para quem quer flertar, namorar ou até subir ao altar. O PP reúne um total de 16 milhões de cadastrados e, segundo o próprio site informa, recebe uma média de 2,5 milhões de visitantes únicos por mês. O PP diz já ter recebido cerca de 6 mil histórias de sucesso de seus usuários, que falavam nos namoros, casamentos e até nos filhos com parceiros que conheceram lá. "Conheci o amor da minha vida através desse site. Hoje, estamos morando juntos e planejamos nos casar ainda este ano", diz uma usuária num dos depoimentos publicados no site como exemplo aos calouros.

Os contatos que tive no PP me permitiram conhecer melhor o universo feminino. Percebi como muitas mulheres, desapontadas com suas relações anteriores, ainda alimentam o desejo de encontrar um príncipe encantado. Encontrei também algumas que se deixavam levar pelo desejo ardente que surgia de nossas conversas até chegar ao orgasmo. Minha experiência do PP me abriu novos horizontes no plano afetivo e sexual. (REVISTA ÉPOCA, publicado em 19/09/2009).

A veiculação da reportagem da revista para versão digital possibilitou aos leitores a interação por meio da interface digital e comprovou com as postagens que o número de pessoas que acessam sites de relacionamento é grande e que esta iniciativa não é apenas algo que os comunicólogos utilizam para evidenciar novos padrões de relacionamentos com o advento da internet. A reportagem da 
revista envolve-se numa nova performance do corpo no meio digital. Perniola ${ }^{23}$ (1998) esclarece que o corpo do qual a sexualidade neutra ${ }^{24}$ possui experiência não é máquina, mas sim roupa, coisa.

Mario Perniola (1998) afirma que:

Os corpos se tornaram rolos de tecido para serem desenrolados e dobrados um sobre o outro, até que finalmente se possa estabelecer uma nova ordem, associando sedas com sedas lãs com lãs, lonas com lonas. Os órgãos são roupas das quais saltam botões e costuras, e que retorna, a condição de pedaços de tecido abertos para serem trabalhados: assim, podem ser unidos e separados segundo novos critérios que não correspondem a nenhuma função e a nenhum escopo (PERNIOLA, 1998, p.29).

Ao indicar essa noção de corpo que se torna veste estranha o autor possibilita uma nova dinâmica e uma performance de desafios pragmáticos na cultura contemporânea. A dimensão das inter-relações sobre o corpo, em decorrência dos processos de interface com o digital e a interatividade tecnológica encontram os corpos de usuários em termos geográficas e virtuais, visto que esse procedimento possibilita a imersão do/no corpo à experiência ciberespacial.

\section{INTERAÇÕES HOMEM/MÁQUINA E CIBERSEXUALIDADE ${ }^{25}$}

$\mathrm{Na}$ grande rede existem pessoas que buscam desde relacionamentos com objetivos reais até relacionamentos puramente virtuais; ou relacionamentos efêmeros ou instáveis e relacionamentos duradouros ou estáveis. Um usuário que

23 Mario Perniola, professor de estética na Universidade de Roma, inspira-se numa frase de Walter Benjamin acerca do "sex appeal do inorgânico" para destacar sobre a sociedade contemporânea, na qual, segundo o autor, tornou-se inorgânica, isto é, compreensível muito mais através dos efeitos perversos das performances que nela se desenvolvem, do que através das ações dos sujeitos projetadores e programadores.

Perniola (1998) passa de uma sexualidade orgânica, orgástica, fundada na diferença dos sexos, dirigida pelo prazer e pelo desejo, para uma sexualidade neutra e por isso inorgânica, artificial, sendo estas as novas formas de experiências do sentir.

25 Alguns estudos (SILVA, 2010; SILVA, 2009), a cibersexualidade aparece, assim, como uma opção válida, tendo em conta o risco de contaminação de doenças infecto-contagiosas e outras complicações que possam advir do sexo casual. Esta é uma das principais características do sexo virtual: fisicamente é totalmente seguro. Psicologicamente pode provocar decepção, ultraje e, até, um grau elevado de dependência. A Internet funciona também como espaço de pesquisa sexual onde existe a possibilidade de exploração dos limites da sexualidade2. Como refere uma cibernauta num estudo sobre cibersexualidade: "Lo hago sólo por ver y sentirme a mi misma, solo para hacer algo nuevo". 
busca uma relação pode estar usando a Internet como uma ponte para o estabelecimento de relacionamentos reais, o que qualifica uma certa forma de objetivo, sendo que o que importa é sair do virtual para encontros face a face ou pode estar usando o meio digital como o próprio espaço poderá se desenvolver a interação, não tendo este nenhum objetivo, por qualquer razão que seja, de se tornar uma relação real.

Para Silva (2009),

As comunidades virtuais proporcionam anonimato e privacidade, formando espaços lúdicos ideais para a experimentação sexual. Nestes laboratórios virtuais possibilitam a recriação, interpretação e aniquilação de todos os tabus. Os ciber-amantes gozam de uma liberdade total, por vezes extrema. É o caso de um clube (criado por mulheres) inspirado em RPGs (rol playing games), cujo tema era a violação. Estas mulheres expõem-se, através da Internet, a violações executadas por elas próprias. De acordo com Sherry Turkle 1 a realidade virtual só pode ser interessante se for baseada a realidade, no entanto também é necessário concretizar virtualmente o que não é concretizável na vida real. Este espaço pleno de significação sexual e social,é propício para simular situações que no plano actual não seriam concretizáveis (SILVA, 2009, 542).

O foco de discussão sobre as interações homem/máquina e as interações possíveis de sexualidade no ciberespaço, aqui nominadas como relações de cibersexualidade não possui o objetivo de discutir se as relações que se estabelecem fazem uso da Internet para a aproximação, não se restringindo as relações humanas do virtual, ou daquelas relações que passam da virtualidade para a realidade. Mas problematizar como se dá o processo através do meio digital de interações, sejam elas com finalidades de encontrar um amor, sexo casual, futuro casamento ou outros.

Alguns estudos mostram que aqueles relacionamentos que se restringem ao campo do virtual, portanto aqueles que não funcionam como um meio para que os participantes se encontrem no mundo real, podem ser vistos como relacionamentos em que os participantes nunca se encontram pessoalmente, relacionamentos que só existem no ciberespaço. Alguns destes relacionamentos virtuais apresentam características próprias relacionamentos reais, mesmo que não o contato real sendo concretizado. Neste caso, sendo a sensibilidade do 
contato real totalmente inexistente, a característica mais marcante neste tipo de relação é extremamente maquínica, ou seja, o corpo físico dos interlocutores de um relacionamento virtual permanece sempre excluído da relação. Cabe ressaltar, que a relação é incorporal.

Dessa ausência de corpo físico decorre uma outra característica importante: a impossibilidade do contato corporal, tanto no sentido sexual quanto no sentido de uma intimidade não sexual. Sendo assim, o prazer sexual muda necessariamente de natureza, o orgasmo vindo por via masturbatória, ou sendo substituído por uma troca de palavras, imagens e sons que alguma outra forma de prazer deve propiciar a seus praticantes. Outra forma sensível que norteia tal relação é a experiência de revelar segredos para um desconhecido que não sabe quem somos pode ser mais fácil de ser realizada do que a de relatar segredos e fantasias para pessoas conhecidas e com as quais convivemos fora do ciberespaço.

No ciberespaço muitos fatores são em grande parte abolidos, de tal modo que há uma maior possibilidade de que se realizem encontros e cruzamentos que por conta dos fatores excludentes do mundo real não poderiam acontecer. Mas é inegável que o potencial segregador do ciberespaço é menor do que o do mundo real. Além disso, deve ser levado em conta que o anonimato proporcionado por esta mediação faz cair as inibições, aumentando o campo de ação dos indivíduos, e isso inclusive no que toca os seus parceiros de relação.

Uma característica importante do ciberespaço e também dos relacionamentos virtuais, é que, sendo virtual, nem por isso deixa de ser extremamente concreto para seus usuários. Isso implica na criação de personagens com que se dialoga no virtual também são percebidos como seres humanos e os sentimentos, as sensibilidades experimentadas são igualmente sentimentos "verdadeiros" ou "reais".

Nicolaci-da-Costa (1998) indica alguns traços da nova lógica instaurada pelos meios informáticos de comunicação: excesso; instauração de um novo tipo de raciocínio mais relativizado, integrado; liberdade de disponibilização e acesso a 
informação etc. A abordagem da autora é a partir do caráter problemático dos relacionamentos virtuais; ela dá a idéia de quem faz somente o uso da tecnologia informática da comunicação para o estabelecimento de relações, não consegue estabelecer pontes de ligação entre as realidades real e virtual.

Alguns aspectos negativos dos relacionamentos virtuais destacados por Nicolaci-da-Costa (1998) são a ilusão de proximidade, conhecimento e intimidade a despeito das, às vezes enormes, distâncias geográficas é um dos contras da virtualidade. Um dos mais sérios é a fuga da realidade "real", quando essa não é, ou não está, das melhores, o que, muito provavelmente, é parte do que está por trás do tão alardeado vício na Rede, principalmente nos chats (NICOLACI-DACOSTA, 1998 p.259). Na ótica da autora. os bons usos da Internet servem para a construção de uma ponte entre real e virtual. O virtual fechado sobre si mesmo é tomado negativo. Todavia, existem aspectos positivos para contrapor.

Esses espaços de relacionamento virtual podem ter o efeito terapêutico de abrir uma brecha na vida de pessoas extremamente oprimidas. "Essas relações de presença-ausência criam através das interações sociais um espaço especial para o desenvolvimento de sentimentos que não existiam antes" (NICOLACI-DACOSTA, 1998 p.326). As relações do virtual podem apresentar às pessoas um mundo de possibilidades até então adormecidas, ou chamar a atenção para a infinitude do campo do possível. Nos chats, as relações podem se moldar com rapidez, mas podem terminar com uma rapidez ainda maior. Basta um clique do mouse para que um usuário seja definitivamente despachado da vida de outro usuário. Nesse contexto, Bauman (2004) reflete:

Das muitas tendências, inclinações e propensões naturais dos seres humanos, o desejo sexual foi e continua sendo a mais óbvia, indubitável e incontestavelmente social. Ele se estende na direção de outro ser humano, exige sua presença e se esforça para transformá-lo em união.Ele anseia por convívio. Torna qualquer ser humano - ainda que realizado e, sob todos os outros aspectos, auto-suficiente - incompleto e insatisfeito, a menos que esteja unido a um outro (BAUMAN, 2004, p.55).

Muitos estudos contemporâneos trazem o argumento que o amor com as máquinas e as aventuras nos mundos virtuais são alternativas bastante sedutoras 
na era da AIDS, das gravidezes não desejadas e das doenças sexualmente transmissíveis. Entre todas as mudanças que estão se dando na sociedade, nenhuma é mais importante do que aquelas que acontecem em nossas vidas pessoais - na sexualidade, nos relacionamentos. Há uma revolução global em curso no modo como pensamos sobre nós mesmos e no modo como formamos laços e ligações com outros. É uma revolução que avança de maneira desigual em diferentes regiões e culturas, encontrando muitas resistências.

Essa revolução global é refletida por Lipovetsky (2004)

\begin{abstract}
Sinônimo de desencantamento com os grandes projetos coletivos, o parêntese pós-moderno ficou, todavia, envolto numa nova forma de sedução, ligada à individualização das condições de vida, ao culto do eu e das felicidades privadas. Já não estamos mais nessa fase: eis agora o tempo do desencanto com a própria pós-modernidade, da desmistificação da vida no presente, confrontada que está com a escalada das inseguranças. $O$ alívio é substituído pelo fardo, 0 hedonismo recua ante os temores, as sujeições do presente se mostram mais fortes que a abertura de possibilidades acarretada pela individualização da sociedade. (LIPOVETSKY, 2004, 65).
\end{abstract}

Como ocorre com outros aspectos do mundo em descontrole, não se sabe ao certo qual virá a ser a relação entre vantagens e problemas. Sob certos aspectos estas são as transformações mais difíceis e perturbadoras de todas. Portanto, não como escapar das mudanças que atingem diretamente o cerne de nossas vidas emocionais. Na fuga da realidade, o homem tem inventado outros mundos para ter compreensão das transformações e dos conceitos contemporâneos.

Segundo Cigini (2009), nesta sociedade líquida, transformada pelo mercado, que rendeu qualquer coisa do valor da mercadoria de consumo, também os valores mais importantes da vida passam pelo mesmo processo de materialização. Assim, o amor, nesta cultura consumista, é tratado à tratado à semelhança de outras mercadorias. Se, tudo muda tão rapidamente e a velocidade é o clima existencial em que o mundo está, que sentido tem investir em algo de duradouro? Se, as ideologias da modernidade estão todas fracassadas, por que investir tempo e energia em algo que passa rapidamente? 
As transformações que afetam as esferas pessoal e emocional vão muito além das fronteiras semântica dos conceitos. A ausência de corpo físico, a impossibilidade do contato corporal em alguns casos, tanto no sentido sexual quanto no sentido de uma intimidade não sexual mostrou que ideologicamente rupturas são absorvidas, a todo o momento, na sociedade. E que mais do que nunca as relações são tidas como efêmeras, passageiras e líquidas, assim como Bauman (2004) classifica o amor, a sociedade e a modernidade.

\section{CONSIDERAÇÕES FINAIS}

$\mathrm{Na}$ realização da leitura crítica sobre a cibersexualidade, a cultura e a sociedade contemporânea nas suas interfaces com a tecnologia e o digital, tentouse examinar algumas questões efervescentes que (inter) conectam os as relações que se estabelecem no ciberespaço. Para tanto, buscou-se primeiramente identificar a compreensão deste sujeito na sua dimensão corpórea - para a partir destas reflexões, refletir sobre as alternativas encontradas na atualidade que podem traduzir os vínculos do corpo digital e as interfaces perpassadas por ele: amor, sexualidade, afetividade e na diversidade de possíveis relações humanas.

Desta forma, a temática em questão traz em sua amplitude uma perspectiva interdisciplinar, que possibilita em muitas das reflexões a complexa sociabilidade oriunda do estudo sobre o corpo, marcando a cultura contemporânea e podendo assim dar um destaque no diálogo entre a arte, a comunicação, a tecnologia e as Ciências Humanas. Ao discutir sobre estas alternâncias enfoques interdisciplinares são criados e várias análises para revisão de diferentes graus de possibilidades corpóreas ampliam a esfera explícita dos objetos aqui analisados.

Com esta ampliação dos sentidos produzidos, as reiterações de novos paradigmas, ambientados pela cultura contemporânea de inclusão digital fazem o corpo como uma representação complexa de sistema que deflagram a diversidade substancial de corpo na atualidade, surgindo novas experiências de troca, 
manifestações e interfaces (homem/máquina), que o corpo expressa diante da cultura contemporânea.

Entre o universo da arte, da ciência e da comunicação, há uma compreensão de que os procedimentos de mediação do corpo remetem a configuração de uma identidade contemporânea, na qual se pode partir de uma concepção entre o real e o virtual e ainda nas relações identitárias por meio da atração do homem pela máquina ou através dos usos da máquina pelo homem. Pôde-se, contudo, desmistificar, neste âmbito de discussão, que o entrecruzamento entre os campos de conhecimento que conciliam a dimensão tecnológica, trazem como consequências novas formações do sujeito pósmoderno e inúmeras possibilidades no ciberespaço, no quais alteram as relações humanas, a identidade, o tempo e o espaço.

\section{REFERÊNCIAS}

BAUMAN, Zygmunt. Amor líquido: sobre a fragilidade dos laços humanos. Tradução: Carlos Alberto Medeiros. Rio de Janeiro: Jorge Zahar, 2004.

. Modernidade Líquida. São Paulo: Paulus, 1998.

CAMARGO, Francisco Carlos; HOFF, Tânia M. Cezar. Erotismo e Mídia. Rio de Janeiro: Àgora da llha, 2002.

CIGINI, P. Identidade, Afetividade e as Mudanças Relacionais na Modernidade Líquida de Zygmunt Bauman. Diálogos Possíveis. Jan./jun. São Paulo: 2009.

FOFONCA, Eduardo. Comunicação e Educação. Conexões em tempos de sociabilidade e convergência digital. Curitiba: Editora CRV, 2012.

GARCIA, Wilton. Corpo, Mídia e Representação: estudos contemporâneos. São Paulo: Pioneira Thomson Learning, 2005.

GIDDENS, A. A transformação da intimidade. São Paulo: Editora Unesp, 1992. As conseqüências da modernidade. Oeiras : Celta Editora, 1992.

GONÇALVES, M. S. Comunicação, virtual e amor na sociedade contemporânea. Tese de Doutorado, Escola de Comunicação, Universidade Federal do Rio de Janeiro, 2000. 
KERCKHOVE. Derrick. de. A Pele da Cultura: investigando a nova realidade eletrônica. São Paulo: Annablume, 2009.

LEIS, H. R. A. A tristeza de ser sociólogo no século XXI. Dados. V. 43. N.4, out./dez.2000.

. Sobre o conceito de interdisciplinaridade. Cadernos de Pesquisa Interdisciplinar em Ciências Humanas, n.73, ago. 2005.

LEMOS, A. Cibercultura, tecnologia e vida social na cultura contemporânea. Porto Alegre: Sulina, 2002.

LÉVY, P. As tecnologias da inteligência: o futuro do pensamento na era da informática. Rio de Janeiro: Ed 34, 1995.

A Inteligência Coletiva: por uma antropologia do ciberespaço. 2. ed. São Paulo: Loyola, 1999.

LIPOVETSKY, G. Os tempos hipermodernos. Tradução: Mário Vilela. São Paulo: Barcarola, 2004.

NICOLACI-DA-COSTA, A. M. Na Malha da Rede - Os impactos íntimos da Internet, Rio de Janeiro: Campus, 1998.

PERNIOLA, Mario. O Sex Appeal do Inorgânico. São Paulo: Studio Nobel, 1998.

PORTO, S. D. (Org.) Sexo, afeto e era tecnológica: Um estudo de chats na Internet, Brasília: Editora Universidade de Brasília,1999.

REVISTA ÉPOCA. Minha vida amorosa na internet. Edição Setembro de 2009. Editora Globo. Disponível em http://revistaepoca.globo.com/Revista/Epoca/0,EMI93880-15228,00-

MINHA+VIDA+AMOROSA+NA+INTERNET.html. Acesso em 10 de maio de 2012.

ROSSET, C. O real e seu duplo, São Paulo: L\&PM, 1988.

SILVA, L. A. V. Cybersexuality and online research: some reflections about the concept of barebacking. Interface - Comunicação, Saúde, Educação, v.14, n.34, p.513-27, jul./set. 2010.

SILVA, B. M. da. Cibersexo. Congresso 6o SOPCOM/8 LUSOCOM, Portugal, 2009. 